\title{
Microscopic Versus Endoscopic Myringotomy with/without Grommet Insertion
}

\author{
Original \\ Ajay Mundru', Deviprasad Dosemane ${ }^{2}$, Panduranga M. Kamath ${ }^{3}$, Suja S. \\ Article \\ Sreedharan $^{4}$, Vijendra Shenoy \\ ${ }^{1}$ Kondaveedu ENT Hospital, Narsaraopet, India, ${ }^{2,3,4,5}$ Department of Otorhinolaryngology, \\ Kasturba Medical College, Manipal Academy of Higher Education, India.
}

\begin{abstract}
Aim: Otitis Media with Effusion (OME) in children requires myringotomy, which is usually done under microscope. Use of endoscope in ear surgeries has increased. So we compared outcome of myringotomy under microscope and endoscope. Patients and Methods: Time bound descriptive non-randomized study was done in a tertiary care hospital on 3-13 year's old children with OME, with 'B' type tympanogram. Myringotomy \pm grommet insertion was done either under microscope or endoscope. Primary outcome observed was time taken for various steps of procedure. Additional observations like narrow canal, overhang and injury of ear canal; visualization of entire tympanic membrane (TM), satisfactory clarity of view and depth perception were noted.

Results: Out of 33 patients, 18 and 13 underwent procedure under microscope and endoscope respectively. Time for myringotomy on right side under microscope was 80.73 seconds, under endoscope was 30.63 seconds $(P<0.001)$; on left side under microscope was 59.08 seconds, under endoscope was 35.41 seconds $(P<0.001)$. Time between procedure on one ear and contralateral ear was 151.53 seconds under microscope and 60.23 seconds under endoscope $(P<0.001)$. Endoscopic grommet insertion took longer than microscopic technique on right ear $(P=0.037)$. Under endoscope, ability to visualize entire TM, satisfactory clarity of view and depth perception were statistically significant $(P<0.001)$.

Conclusion: Less operative time, satisfactory depth perception, clarity of field and visualizing of entire TM make myringotomy \pm grommet insertion with endoscope a better alternative than microscopic procedure.
\end{abstract}

Key Words: Endoscopic, grommet, microscopic, Mmyringotomy, otitis media with effusion.

Received: 16 December 2019, Accepted: 24 April 2020

Corresponding Author: Deviprasad Dosemane, MD, Department of Otorhinolaryngology, Kasturba Medical College, Mangalore, Manipal Academy of Higher Education. India., Tel.: +91-990135975, E-mail: dr.deviprasad@yahoo.com

ISSN: 2090-0740, November 2020 Vol.21, No.3

\section{INTRODUCTION}

Otitis media with effusion (OME) is a common medical problem in young children and may need myringotomy. Armstrong reintroduced the middle ear ventilation tubes, which was done using a microscope..$^{[1],[2]}$. Ear surgeries are regularly done nowadays using an endoscope. ${ }^{[3],[4]}$.

The aim of our study was to set a comparison between microscopic and endoscopic myringotomy with or without grommet insertion. The objectives of the study were as follows: 1) To compare time taken for myringotomy using microscope and endoscope, 2) To compare time taken for grommet insertion using microscope and endoscope, 3) To find out the advantages and disadvantages of doing myringotomy using microscope and endoscope.

\section{PATIENTS AND METHODS:}

\section{1- Study design, setting and Study duration:}

This time bound descriptive non-randomized study was conducted over 2 years in our tertiary care hospital after the clearance from the ethical committee of the University.

\section{2- Study population, Sample size and sampling}

\section{technique:}

All 3-13 year old cases of OME who fulfilled following criteria were included in the study; 1) who failed medical management: i.e., persistent OME after at least 3 weeks therapy with nasal with or without oral decongestants, oral mucolytics and oral steroids with or 
without nasal steroid sprays 2) showed conductive hearing loss on pure tone audiometry (i.e., with a minimum of $15 \mathrm{~dB}$ Air-Bone Gap) and 3) showed B type curve in tympanogram. The following patients were excluded from the study; 1) patients with $\mathrm{C}$ or Cs types of curve in tympanogram, 2) acute otitis media and 3 ) patients with adhesive otitis media. The patients who fulfilled the criteria were arbitrarily allocated to either of the 2 groups. In one group conventional microscopic myringotomy with or without grommet insertion was performed whereas in the other group endoscopic myringotomy with or without grommet insertion was performed. All the endoscopic myringotomies were performed by a single surgeon. Microscopic myringotomies performed by 2 different surgeons and their experiences and expertise were comparable. All were right handed surgeons. They were seated beside the patients' shoulder, at the head end, on right side of the patients to operate on right ear and on the left side of the patients to operate on left ear. Written informed consents were taken from the parents/guardian of the subjects.

\section{3-Surgical techniques:}

Surgical procedure- Under General Anesthesia, the external auditory canal was visualized under microscope in conventional method and with a pediatric endoscope $\left(0^{\circ}, 2.7 \mathrm{~mm}\right)$ in the endoscopic group. Suctioning was done to remove wax, debris if any before starting the procedure and this time was excluded. Now myringotome was held and incision was made in the anteroinferior quadrant. Time was noted from the point of onset of effort in focusing the tympanic membrane to the point of making incision in it with a myringotome. Secretions and blood were suctioned out. Timing for suctioning of these fluids was excluded. Grommet was held with crocodile forceps and placed in the myringotomy incision under microscopic vision in conventional group, whereas in endoscopic group it was inserted under vision of pediatric endoscope and time was calculated for this step. For performing the procedure in the other ear, Microscope was shifted to the other side in conventional group, whereas in the endoscopic group, the head was turned to other side and same procedure was repeated. This interval time between the procedure on one ear and contralateral ear was calculated. Lee, in 2006 did a study and suggested that for safe and effective otoendoscopic grommet insertion it's better to select children above 6 years. ${ }^{[5]}$ So we also compared the time taken for various procedures for children $<6$ years and $>6$ years in both the groups. Additional observations like narrow outer ear canal, overhang and injury of ear canal; visualization of entire tympanic membrane, satisfactory clarity of view and depth perception were noted on both sides for both types of procedures.

\section{4- Data analysis:}

The data was summarized using tables. Statistical analysis of the data was done by using Student's t-test, Chi square test and Mann-Whitney ' $U$ ' test. Statistics was analyzed with SPSS version 17.0. $P<0.05$ was considered statistically significant.

\section{RESULTS:}

\section{1-Microscopic myringotomy:}

The total number of patients who underwent this procedure were 18 , out of which 10 patients were boys and 8 patients were girls. The mean age of the patients was 5.94 years. 'The procedure was done on both sides in 17 patients and on the right side only in 1, who also had a grommet inserted. Five patients out of 17 who underwent bilateral myringotomy did not require any grommet insertion. The time taken for the procedures is detailed in (Table 1).

\section{2- Endoscopic myringotomy:}

The total number of patients who underwent this procedure was 15 , out of which 8 patients were males and 7 patients were females. The mean age of the patients was 6.53 years. All the 15 patients underwent bilateral myringotomy, out of which, 2 patients required only unilateral grommet insertion and 4 patients did not require any grommet insertion. Grommet insertion was done only in cases where the effusion in the middle ear was visualized and suctioned out Intra-operatively. The time taken for the procedures is detailed in (Table 1). Between the two groups, comparison of the time taken (in sec) for various procedures were statistically significant, except for the time taken for grommet insertion in left ear.

Children were also divided on the basis of age into below 6 years and 6 years and above. The time was compared in both the procedures separately. Eleven and 6 children were below the age of 6 years in microscopic and endoscopic groups respectively. Time taken for microscopic myringotomy in children $<6$ years is $76.0722 .09 \pm \mathrm{sec}$ where as it was $5121.47 \pm \mathrm{sec}$ in children above 6 years. For grommet insertion it took $108.01173 .37 \pm \mathrm{sec}$ for $<6$ years where as $78.3238 .75 \pm \mathrm{sec}$ for children $>6$ years. In the endoscopic group for children $<6$ years, time for myringotomy was $30.7610 .99 \pm \mathrm{sec}$ and grommet insertion was 108.2592.2 $\pm \mathrm{sec}$. But for children $>6$ years age it took $36.4112 .52 \pm$ sec for myringotomy and 139.683.24 sec for grommet insertion. Out of these, we found that, only the time taken (in sec) for myringotomy in microscope group was higher in $<6$ years group with a $t$ value of 2.19 and had a statistically significant association $(P$ value $=0.036)$.

Additional observations in microscopic and endoscopic groups are detailed in (Table 2). 
Table 1: Comparison of time between the two procedures in each ears separately. $(\mathrm{R})=$ right, $(\mathrm{L})=$ left, $\mathrm{sec}=$ seconds.

\begin{tabular}{|c|c|c|c|c|c|c|c|}
\hline Time taken for & GROUP & Count & Mean (sec) & Std. Deviation & $\mathrm{t}$ & $\mathrm{df}$ & $P V A L U E$ \\
\hline \multirow{2}{*}{$\begin{array}{l}\text { myringotomy } \\
(\mathrm{R}) \text { ear }\end{array}$} & $\begin{array}{l}\text { MICROSCOPIC } \\
\text { MYRINGOTOMY }\end{array}$ & 18 & 80.73333 & 24.28449 & \multirow{2}{*}{7.553} & \multirow{2}{*}{26.82} & \multirow{2}{*}{$<0.001$} \\
\hline & $\begin{array}{c}\text { ENDOSCOPIC } \\
\text { MYRINGOTOMY }\end{array}$ & 15 & 30.63867 & 12.9745 & & & \\
\hline \multirow{2}{*}{$\begin{array}{l}\text { myringotomy } \\
\text { (L) ear }\end{array}$} & $\begin{array}{l}\text { MICROSCOPIC } \\
\text { MYRINGOTOMY }\end{array}$ & 17 & 59.08765 & 15.77246 & \multirow{2}{*}{4.954} & \multirow{2}{*}{30} & \multirow{2}{*}{$<0.001$} \\
\hline & $\begin{array}{c}\text { ENDOSCOPIC } \\
\text { MYRINGOTOMY }\end{array}$ & 15 & 35.416 & 10.27677 & & & \\
\hline \multirow{2}{*}{$\begin{array}{l}\text { grommet } \\
\text { insertion }(\mathrm{R}) \text { ear }\end{array}$} & $\begin{array}{l}\text { MICROSCOPIC } \\
\text { MYRINGOTOMY }\end{array}$ & 13 & 71.58154 & 40.42646 & \multirow{2}{*}{-2.224} & \multirow{2}{*}{21} & \multirow{2}{*}{0.037} \\
\hline & $\begin{array}{c}\text { ENDOSCOPIC } \\
\text { MYRINGOTOMY }\end{array}$ & 10 & 130.996 & 85.036 & & & \\
\hline \multirow{2}{*}{$\begin{array}{l}\text { grommet } \\
\text { insertion (L) ear }\end{array}$} & $\begin{array}{l}\text { MICROSCOPIC } \\
\text { MYRINGOTOMY }\end{array}$ & 12 & 122.7508 & 191.3343 & \multirow{2}{*}{0.02} & \multirow{2}{*}{20} & \multirow{2}{*}{0.984} \\
\hline & $\begin{array}{c}\text { ENDOSCOPIC } \\
\text { MYRINGOTOMY }\end{array}$ & 10 & 121.417 & 91.08901 & & & \\
\hline \multirow{2}{*}{$\begin{array}{l}\text { between the } \\
\text { procedure } \\
\text { on one ear \& } \\
\text { contralateral ear }\end{array}$} & $\begin{array}{l}\text { MICROSCOPIC } \\
\text { MYRINGOTOMY }\end{array}$ & 17 & 151.5335 & 38.96677 & \multirow{2}{*}{7.378} & \multirow{2}{*}{30} & \multirow{2}{*}{$<0.001$} \\
\hline & $\begin{array}{c}\text { ENDOSCOPIC } \\
\text { MYRINGOTOMY }\end{array}$ & 15 & 60.23 & 29.66281 & & & \\
\hline
\end{tabular}

Table 2: Comparison of additional observations between the two procedures. $(\mathrm{R})=$ right, $(\mathrm{L})=$ left \& TM = Tympanic Membrane.

\begin{tabular}{|c|c|c|c|c|c|c|c|}
\hline \multicolumn{8}{|c|}{ GROUP } \\
\hline & & \multicolumn{2}{|c|}{$\begin{array}{l}\text { MICROSCOPIC } \\
\text { MYRINGOTOMY }\end{array}$} & \multicolumn{2}{|c|}{$\begin{array}{c}\text { ENDOSCOPIC } \\
\text { MYRINGOTOMY }\end{array}$} & \multirow[t]{2}{*}{ Chi square } & \multirow[t]{2}{*}{$P$ value } \\
\hline & & Count & Column N \% & Count & Column N \% & & \\
\hline \multirow{2}{*}{$\begin{array}{l}\text { Narrow }(R) \\
\text { outer ear canal }\end{array}$} & no & 11 & $61.10 \%$ & 9 & $60.00 \%$ & 0.004 & 0.948 \\
\hline & yes & 7 & $38.90 \%$ & 6 & $40.00 \%$ & & \\
\hline \multirow{2}{*}{$\begin{array}{l}\text { Narrow }(\mathrm{L}) \\
\text { outer ear canal }\end{array}$} & no & 14 & $82.40 \%$ & 13 & $86.70 \%$ & 0.112 & 0.737 \\
\hline & yes & 3 & $17.60 \%$ & 2 & $13.30 \%$ & & \\
\hline \multirow{2}{*}{$\begin{array}{l}\text { anterior canal over } \\
\text { hanging }(R) \text { ear }\end{array}$} & no & 15 & $83.30 \%$ & 11 & $73.30 \%$ & 0.49 & 0.484 \\
\hline & yes & 3 & $16.70 \%$ & 4 & $26.70 \%$ & & \\
\hline \multirow{2}{*}{$\begin{array}{l}\text { anterior canal over } \\
\text { hanging }(\mathrm{L}) \text { ear }\end{array}$} & no & 15 & $88.20 \%$ & 9 & $60.00 \%$ & 3.388 & 0.066 \\
\hline & yes & 2 & $11.80 \%$ & 6 & $40.00 \%$ & & \\
\hline \multirow{2}{*}{$\begin{array}{l}\text { canal injury by } \\
\text { instrumentation } \\
\text { (R) right ear }\end{array}$} & no & 15 & $83.30 \%$ & 8 & $53.30 \%$ & 3.487 & 0.062 \\
\hline & yes & 3 & $16.70 \%$ & 7 & $46.70 \%$ & & \\
\hline \multirow{2}{*}{$\begin{array}{l}\text { canal injury by } \\
\text { instrumentation } \\
\text { (L) ear }\end{array}$} & no & 15 & $88.20 \%$ & 11 & $73.30 \%$ & 1.162 & 0.281 \\
\hline & yes & 2 & $11.80 \%$ & 4 & $26.70 \%$ & & \\
\hline \multirow{2}{*}{$\begin{array}{l}\text { entire TM } \\
\text { visualized without } \\
\text { adjusting patients } \\
\text { head (R) ear }\end{array}$} & no & 18 & $100.00 \%$ & 0 & $0.00 \%$ & 33 & $<0.001$ \\
\hline & yes & 0 & $0.00 \%$ & 15 & $100.00 \%$ & & \\
\hline \multirow{2}{*}{$\begin{array}{l}\text { entire TM } \\
\text { visualized without } \\
\text { adjusting patients } \\
\text { head (L) ear }\end{array}$} & no & 17 & $100.00 \%$ & 0 & $0.00 \%$ & 32 & $<0.001$ \\
\hline & yes & 0 & $0.00 \%$ & 15 & $100.00 \%$ & & \\
\hline \multirow{2}{*}{$\begin{array}{l}\text { satisfactory } \\
\text { clarity of view }\end{array}$} & no & 18 & $100.00 \%$ & 0 & $0.00 \%$ & 33 & $<0.001$ \\
\hline & yes & 0 & $0.00 \%$ & 15 & $100.00 \%$ & & \\
\hline \multirow{2}{*}{$\begin{array}{l}\text { satisfactory depth } \\
\text { perception }\end{array}$} & no & 18 & $100.00 \%$ & 0 & $0.00 \%$ & 33 & $<0.001$ \\
\hline & yes & 0 & $0.00 \%$ & 15 & $100.00 \%$ & & \\
\hline
\end{tabular}




\section{DISCUSSION}

"Otitis media with effusion (OME) is the chronic accumulation of mucous within the middle ear and sometimes the mastoid air cell system". ${ }^{[6]}$ It is treated by medical management using oral / nasal decongestants, oral antihistamines, nasal steroids, mucolytics etc. There is no consensus in the literature about the specific combination of these medications and the duration of treatment before it is stopped. But the general understanding is that, if the medical management fails, myringotomy is performed. Myringotomy (for OME) is a surgical procedure in which a small radial incision is usually made in the anteroinferior part of tympanic membrane. In addition to this, grommets or ventilation tubes or tympanostomy tubes are inserted into the incision site of tympanic membrane in some cases of OME for ventilation of middle ear, usually depending on the amount and nature of middle ear effusion intraoperatively.

The primary outcome observed was time taken for the procedure. We observed that time taken for myringotomy by conventional microscope was more than that of endoscopic procedure. Martellucci et al. in 2015 had done a pilot study in adults and observed that time taken for endoscopic procedure was $10.14 \pm 3.13$ minutes and microscopically it was $10.92 \pm 3.99 \mathrm{sec}$, hence found no statistically significant difference in the operative times required. ${ }^{[7]}$ According to another study done by Alalem RK and Essaket in 2015 it was found that the average operative time was $5.71 \pm 2.27 \mathrm{~min}$ in endoscopic technique and $7.10 \pm 2.36 \mathrm{~min}$ in microscopic technique. ${ }^{[8]}$ The difference in time observed in all these studies may be attributed to the fact that, time calculated for duration of surgery was from the moment the surgeon started receiving instruments from nurse till the procedure is concluded when the nurse receives back the tool from the surgeon, while in our study the operative time was calculated for myringotomy and grommet insertion separately. In our study, we observed that the statistically non-significant timings in grommet insertion was probably due to the fact that grommet insertion in left ear was little difficult as all the surgeons who operated were right handed.

In a study done by Nassif et al. in 2014, it was observed that time taken for endoscopic group was more than that of conventional otomicroscope, which was not the case in our study. In our study, mean time spent between the procedure in one ear and contralateral ear in microscopic group was more than that of endoscopic group $(P$-value of $<0.001)$. This was consistent with the results of the study done by Nassif et al., who mentioned that switching from one side to the other with the endoscope is faster than that of microscope repositioning. ${ }^{[9]}$ After a few endoscopic procedures, we felt that time for endoscopic procedure (especially for the left ear) could have been lowered further if surgeon stood at the head end of patient instead of the right side of the patient, but to maintain uniformity for all cases we did all procedures standing on the right side of the patient.

Lee, in 2006 did a study and suggested that for safe and effective oto-endoscopic grommet insertion it is better to select children above 6 years. ${ }^{[5]}$ In our study, age-related limitations were not encountered in endoscopic group but in microscopic group, the time taken for myringotomy was statistically significantly higher in children $<6$ years $(P$ value $=0.036)$.

Coming to the additional observations, in our study, narrow outer ear canal was observed in $10(28.60 \%)$ out of 35 ears which underwent microscopic myringotomy and $8(26.70 \%)$ out of 30 ears which underwent endoscopic myringotomy. It was noticed that it was little difficult for grommet insertion with endoscope in narrow outer ear canal, but none of the endoscopic procedures were converted to microscopic for insertion of grommet. This was consistent with the study done by Nassif et al., who reported that no endoscopic managements were abandoned or converted to the use of microscope. ${ }^{[9]}$ In our study, anterior canal wall overhanging was noticed in $5(14.30 \%)$ ears of microscopic group and $10(33.30 \%)$ ears of endoscopic group. Canal wall injury by instrumentation was there in both the groups but was seen only in 5 cases $(14.30 \%)$ of microscopic group but 11 cases $(36.70 \%)$ of the endoscopic group making it statistically significant ( $P$-Value of 0.037). More canal wall injuries and bleeding in case of endoscopic group was observed in view of narrow canal and also probably because of learning curve of surgeons. This limitation of bleeding in endoscopic surgeries was mentioned in various studies, where surgeon sometimes is forced to convert the procedure into an oto-microscopic technique, ${ }^{[6]}$ which did not happen for any of the cases of our study. Other observations done like visualizing entire tympanic membrane without adjusting patients head, satisfactory clarity of view and satisfactory depth perception was possible in all $(100 \%)$ patients in endoscopic group but none of them was possible in microscopic group. These differences were statistically significant $P<0.001$ ). This observation was consistent with Alalem and Essaket (2015) who opined that in endoscopic technique the surgeon and the assistants can visualize the whole tympanic membrane and the ear canal. ${ }^{[8]}$ As this study design required documentation of subjective observations under microscope and endoscope by 3 different surgeons and this could no way be "blinded", observers' bias is possible and is a definite limitation of this study. 
Ear surgeries with an endoscope, requiring handeye coordination is not an easy skill to acquire. According to literature, many believe that vast experience and confidence with endoscopic sinus surgery would help rapidly in the improvement of use and manipulation of an oto-endoscope. ${ }^{[10]}$ Myringotomy with or without grommet insertion is considered one of the basic steps in the learning curve of ear surgeons. Endoscopic approach for this simple procedure would be very useful for surgeons who would like to start endoscopic ear surgery. ${ }^{[11]}$ As opined by many otologists, manipulation with single handedness in oto-endoscopy is difficult. ${ }^{[12]}$ However, nowadays, endoscope holders are available to enable the surgeon to use both his hands. Other complications like injury to canal, difficulty in insertion of grommet in narrow canal wall also appear to be a limitation. ${ }^{[8]}$ But these can be overcome with experience. Magnified view of the surgical field on the monitor enables better teaching for residents.

\section{CONCLUSION}

Less operative time, satisfactory depth perception, satisfactory clarity of field and visualizing of entire tympanic membrane without turning the patient head makes myringotomy with or without grommet insertion with endoscope a better technique than a conventional microscopic procedure. Though there are some limitations, those can be overcome with experience.

\section{CONFLICT OF INTEREST}

There are no conflicts of interest.

\section{REFERENCES}

1. Hellstrom S, Groth A, Jorgensen F, Pettersson A, Ryding M, Uhlen I, et al. Ventilation tube treatment: a systematic review of the literature. Otolaryngol Head Neck Surg. 2011; 145(3):383-395.

2. Rimmer J, Giddings CE, Weir N. History of myringotomy and grommets. J Laryngol Otol. 2007; 121(10):911-916.
3. Marchioni D, Alicandri-Ciufelli M, Molteni G, Genovese E, Presutti. Endoscopic tympanoplasty in patients with attic retraction pockets. Laryngoscope. 2010; 120(9):1847-1855.

4. Tarabichi M. Endoscopic transcanal middle ear surgery. Indian J Otolaryngol Head Neck Surg. 2010; 62(1): 6-24

5. Lee, F.P. An alternative use of video-telescopic guidance for insertion of myringotomy tube. $\mathrm{J}$ Laryngol. Otol. 2006; 120(2): e10.

6. Browning GG (2008). Otitis media with effusion. In: Glesson M; Scott-Brown's Otolaryngology, Head and Neck surgery V2, 877, 7th ed. Hodder Arnold; London.

7. Martellucci, S., Pagliuca, G., de Vincentiis, M., De Virgilio, A., Fusconi, M., Gallipoli C. et al, Myringotomy and ventilation tube insertion with endoscopic or microscopic technique in adults: a pilot study. Otolaryngol. Head Neck Surg. 2015; 152(5): 927-930.

8. Allen RK and Saket OJ (2015). Evaluation of the Safety and Effectiveness of Endoscopic Myringotomy and Ventilation Tube Placement. Int. J. Curr. Res. Biosci. Plant Biol.; 2(10): 42-46.

9. Nassif N, Redaelli De Zinis L, Berlucchi M, Zanetti D. Endoscopic ventilation tube placement in the pediatric age. Clin. Otolaryngol.2014; 39(1): 50-53.

10. Presutti L, Gioacchini FM, Alicandri-Ciufelli M, Villari D, Marchioni D. Results of endoscopic middle ear surgery for cholesteatoma treatment: a systematic review. Acta Otorhinolaryngol Ital. 2014; 34(3):153-157.

11. Pothier DD. Introducing endoscopic ear surgery into practice. Otolaryngol Clin North Am. 2013; 46: $245-255$

12. Tarabichi M. Endoscopic middle ear surgery. Ann Otol Rhinol Laryngol. 1999; 108(1): 39-46. 